\title{
Factors associated with perinatal mortality in Nepal: evidence from Nepal demographic and health survey 2001-2016
}

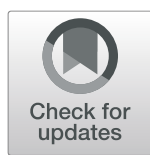

Pramesh Raj Ghimire ${ }^{1 *}$ D, Kingsley E. Agho ${ }^{1}$, Andre M. N. Renzaho ${ }^{2}$, Monjura K. Nisha ${ }^{3}$, Michael Dibley ${ }^{3}$ and Camille Raynes-Greenow ${ }^{3}$

\begin{abstract}
Background: Perinatal mortality is a devastating pregnancy outcome affecting millions of families in many low and middle-income countries including Nepal. This paper examined the more distant factors associated with perinatal mortality in Nepal.

Methods: A sample of 23,335 pregnancies > 28 weeks' gestation from the Nepal Demographic and Health Survey datasets for the period (2001-2016) was analysed. Perinatal Mortality (PM) is defined as the sum of stillbirth (fetal deaths in pregnancies $>28$ weeks' gestation) and early neonatal mortality (deaths within the first week of life), while Extended Perinatal Mortality (EPM) is denoted as the sum of stillbirth and neonatal mortality (deaths within the first 28 days of life). Rates of PM and EPM were calculated. Logistic regression generalized linear latent and mixed models (GLLAMM) that adjusted for clustering and sampling weight was used to examine the factor associated with perinatal mortality.

Results: Over the study period, the PMR was 42 [95\% Confidence Interval (CI): 39, 44] per 1000 births for the five-year before each survey; while corresponding EPMR was $49(95 \% \mathrm{Cl}, 46,51)$ per 1000 births. Multivariable analyses revealed that women residing in the mountains, who did not use contraceptives, women aged 15-18 years or 19-24 years, and women having no education were associated with increased PM and EPM. The study also identified households using biomass as cooking fuel, and households who reported unimproved sanitation or open defecation were significantly more likely to experience PM and EPM.
\end{abstract}

Conclusions: Interventions aimed to improve use of contraceptives, and reduce biomass as a source of cooking fuel are needed to achieve the recommended target of $<12$ perinatal deaths per 1000 births by 2030 .

Keywords: Perinatal mortality, Extended perinatal mortality, NDHS, Nepal

\section{Background}

Availability and quality of healthcare of both mother and newborn is reflected in the perinatal mortality rate, and perinatal mortality remains one of the devastating pregnancy outcomes for millions of families in low-and-middle-income countries including Nepal [1]. A recent Lancet systematic review for the Global Burden of Disease estimated that every year over 4 million perinatal deaths occur worldwide; and almost all (98\%) of these deaths occur in

\footnotetext{
* Correspondence: prameshraj@hotmail.com

${ }^{1}$ School of Science and Health, Western Sydney University, Locked Bag1797, Penrith, NSW 2571, Australia

Full list of author information is available at the end of the article
}

low-and-middle-income countries, mostly in sub-Saharan Africa and South Asia, including Nepal [2]. The perinatal mortality rate is five times higher in low as compared to high income countries, with 10 deaths per 1000 total births in high income countries; 50 per 1000 total deaths in low and middle income countries and over 60 per 1000 in the most deprived countries [1].

In Asia, the perinatal mortality rate is estimated to be 50 per 1000 births, but as high as 65 per 1000 in South-central Asia, the third-highest rate among the sub-regions [1]. Past studies indicated that preterm birth, intrapartum complications and infections are the three leading causes of perinatal death [3], and millions

(c) The Author(s). 2019 Open Access This article is distributed under the terms of the Creative Commons Attribution 4.0 International License (http://creativecommons.org/licenses/by/4.0/), which permits unrestricted use, distribution, and 
of these deaths can be averted with high coverage quality interventions along with a population-specific action plan for women who are socially marginalized based on issues such as ethnicity, geography and socioeconomic status [4]. A case-control study conducted in Pakistan identified that maternal literacy, poor socio-economic household, primigravida, and lack of knowledge of family planning were associated with perinatal mortality [5]. Similarly, a population-based cross-sectional study conducted in Bangladesh that examined the impact of maternal excessive body weight on a range of maternal and child health outcomes reported that overweight and obesity among women aged 25 years and older increased the risk of perinatal mortality by 1.8 [95\% Confidence Interval $(1.5,2.1)][6]$.

Perinatal mortality rates play an increasingly important role in childhood mortality, and there are currently no effective community-based intervention programs in Nepal particularly targeting perinatal mortality including stillbirth. Despite the high burden of perinatal mortality globally, there have been very limited epidemiological studies that examine potential factors associated with perinatal mortality in Nepal. Previous studies conducted in Eastern and Central districts of Nepal found that birth asphyxia, infection, and prematurity were the major causes of stillbirth and neonatal mortality $[7,8]$. A multi-centre prospective study conducted in the Jhapa and Kathmandu districts revealed that higher parity $(>4)$, low birthweight $(<1999 \mathrm{~g})$ and older maternal age ( $\geq 35$ years) were reported to be associated with PM [9]. In contrast, a cross-sectional study conducted in central Nepal found that teenage women were more likely to report higher perinatal mortality [10]. Similarly, another prospective study conducted in Kathmandu concluded that perinatal mortality occurred more frequently among primigravid women, and those having preterm birth reported a higher risk of perinatal mortality [11]. However, the external validity of these studies was limited because they were not population-based, hence may not be generalised to inform effective interventional policy that will significantly reduce perinatal death. The Nepal Demographic and Health Survey (NDHS) dataset provides an opportunity to examine factors associated with perinatal mortality using a population-based sample. Using a national population-based sample will allow the formulation of an integrated policy and programmatic response to address perinatal mortality in Nepal.

The main aim of this study was to determine more distant factors associated with Perinatal Mortality (PM) and Extended Perinatal Mortality (EPM) by using the four most recent nationally representative household data of NDHS for the years 2001, 2006, 2011, and 2016.

\section{Methods}

\section{Data sources and sample}

This study combined data of NDHS for the years 2001 [12], 2006 [13], 2011 [14] and 2016 [15]; which were nationally representative household surveys, using multistage cluster sampling designs, stratified by geographical regions and urban and rural areas. All four surveys sampling methods were similar and routinely collected with the objective of estimating socio-demographic; and maternal and child health indicators at national and district level.

A total of 32,193 women aged 15-49 years were interviewed in the four surveys (8726 women in 2001 NDHS, 10,793 women in 2006 NDHS, 12,674 women in 2011 NDHS, and 12,862 in 2016 NDHS), with the average response rate over 97\%. In the 2001 NDHS [12] women were asked to report all pregnancies they had in their lifetime records of pregnancy loss and the duration of such pregnancies included; whereas in the 2006 NDHS [13], the 2011 NDHS [14], and the 2016 NDHS [15] women were asked to report on any pregnancy loss and the duration of such pregnancy that occurred five years preceding the surveys. Information such as pregnancy, pregnancy loss and duration of pregnancy was used to identify the number of livebirth, stillbirth and pregnancies $>28$ weeks' gestation. For this study 23,335 pregnancies $>28$ weeks' gestation were identified $(N=7134$ in 2001, $N=5671$ in 2006, $N=5444$ in 2011, and $N=5086$ in 2016). Details of the survey methodology, sampling procedures, and questionnaires are provided in the respective NDHS reports [12-15].

\section{Outcome}

Outcome variables for this study were: (I) Perinatal Mortality (PM) defined as the sum of stillbirth (fetal deaths in pregnancies $>28$ weeks' gestation) and early neonatal mortality (deaths within the first week of life) [12-15], and (II) Extended Perinatal Mortality (EPM) defined as the sum of stillbirth and neonatal mortality (deaths within the first 28 days of life) [12-16].

\section{Potential explanatory variables}

The selection of potential explanatory variables for this study was based on past studies that have examined factors associated with perinatal mortality in different low-and middle-income countries [9, 17-19]. We also adopted Mosley and Chen's analytical framework for the study of child survival in low income countries [20]. Figure 1 illustrates the factors used to examine their relation with PM and EPM in that framework. Based on Mosley and Chen's framework, 19 explanatory variables were classified into five categories as community level factors (types of residence and ecological zone); socioeconomic factors (wealth index, religion, mother's education, mother's literacy level, 


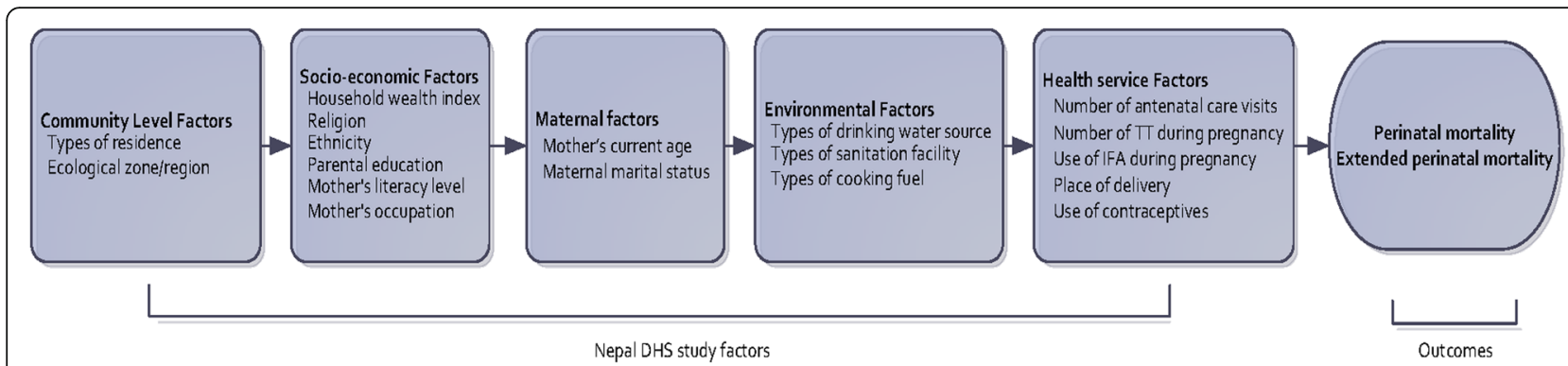

Fig. 1 Framework for factors associated with perinatal mortality in Nepal, adopted from Mosley and Chen analytical framework for the study of child survival in low income countries

father's education and mother's occupation); maternal factors (mother's current age, maternal marital status, and birth order and birth interval); environmental factors (types of drinking water sources, types of sanitation facility and types of cooking fuel); and health service factors (number of antenatal care visits, number of Tetanus Toxoid (TT) vaccines during pregnancy, place of delivery and use of contraceptives). Birth order and birth interval were combined because a previous study found that the impact of birth order may be mediated by birth interval [21]. A household wealth index variable was constructed using principle component analysis [22] of the common household facilities across four NDHS, 2001-2016 (electricity, radio, television, bicycle, telephone, and main material of floor). For the purpose of this study, the household wealth index was divided into three categories. The bottom $40 \%$ of households were arbitrarily referred to as poor households, the next $40 \%$ was classified as the middle households and the top $20 \%$ was classified as rich households, consistent with previous studies $[18,21]$.

The World Health Organization and the United Nations Children's Fund Joint Monitoring Program guidelines were used to categorize the source of drinking water and types of sanitation facility [23]. Categories of source of drinking water included (1) piped water on premises, (2) other improved drinking water sources, (3) unimproved drinking water sources, and (4) surface drinking water sources. Households with piped water system into dwelling were categorised as piped water on premises. Households relying on neighbour's tap or tubewell, borehole in yard, stone tap, protected well and rainwater for drinking were categorised as other improved drinking water sources. Households who reported unprotected well in-house, unprotected public or neighbour's well, unprotected spring, bottled water or water from tanker or truck as sources of drinking water were categorised as unimproved water sources. Households who reported river, stream, pond, lake, dam, canal, or irrigation water for drinking were categorised as surface drinking water sources. Likewise, categories of sanitation facility included (1) improved sanitation facilities, (2) unimproved sanitation facilities, and (3) open defecation. Households having flush toilet, ventilated or improved pit latrine, pit latrine with slab or composting toilet were categorised as improved sanitation facilities. Households who reported traditional pit toilet, pit latrine without slab, bucket toilet were categorised as unimproved sanitation facilities. Households relying on bush or open field for defecation were categorised as open defecation.

\section{Statistical analysis}

Weighted frequencies for all explanatory variables were calculated (Table 2). Perinatal Mortality Rate (PMR) and Extended Perinatal Mortality Rate (EPMR) with 95\% confidence interval across all explanatory variables were calculated (Table 2). The sample was restricted to five years preceding each survey. Data were analysed using STATA 14.1 (Stata Corp, College Station, Texas, US). SVY functions were used to adjust for sampling weights. Logistic regression generalized linear latent and mixed models (GLLAMM) with the logit link and binomial family [24] that adjusted for clustering and sampling weights were used to measure the level of association between outcomes and explanatory variables. Multivariate analysis was conducted using staged technique described by Victora et al. [25] and based on this technique, the effect of distal determinants can be assessed without adjustment of proximal or intermediate determinants [21]. Therefore, at the first stage, all community-level factors (more distal determinants) were assessed in the baseline multivariable model with manual backward elimination to keep statistically significant factors (model 1). Second, socioeconomic factors were added with model 1 and manual backward elimination process was repeated to keep statistically significant factors (model 2). This procedure was followed when maternal, environmental and health service variables were included in the third (model 3), in the fourth (model 4) and in the fifth stage (model 5) respectively. Variables significantly associated at the $5 \%$ significance level were included in model 5 and reported in the study. In the final model (Model 5), we tested and reported any collinearity. Unadjusted and adjusted odd ratios with $95 \%$ confidence interval of the final model were reported. 
Table 1 Rates and 95\% Confidence Intervals (Cl) of stillbirth, early neonatal mortality, late neonatal mortality, neonatal mortality, perinatal mortality, and extended perinatal mortality in Nepal (2001-2016)

\begin{tabular}{|c|c|c|}
\hline Birth and mortality rate & Birth/Mortality & Rate $(95 \% \mathrm{Cl})$ \\
\hline All births, $N^{a}$ & 23,335 & - \\
\hline $\begin{array}{l}\text { Stillbirth, rate }{ }^{\mathrm{b}} \text { per } 1000 \\
\text { births }(95 \% \text { Cl) }\end{array}$ & 414 & $18(16,19)$ \\
\hline $\begin{array}{l}\text { Early neonatal mortality, rate } \\
\text { per } 1000 \text { live births }(95 \% \mathrm{Cl})\end{array}$ & 561 & $24(22,27)$ \\
\hline $\begin{array}{l}\text { Late neonatal mortality, rate }{ }^{d} \\
\text { per } 1000 \text { live births }(95 \% \text { Cl) }\end{array}$ & 160 & $7(6,8)$ \\
\hline $\begin{array}{l}\text { Neonatal mortality, rate } e^{e} \text { per } \\
1000 \text { live births }(95 \% \mathrm{Cl})\end{array}$ & 721 & $31(29,34)$ \\
\hline Perinatal mortality, rate $(95 \%$ Cl) & 975 & $42(39,44)$ \\
\hline Extended perinatal mortality, & 1135 & $49(46,51)$ \\
\hline
\end{tabular}

rate $^{g}(95 \%$ Cl)

${ }^{\mathrm{a}} \mathrm{N}$ included stillbirths and live births from pregnancies $>28$ weeks' gestation ${ }^{\mathrm{b}}$ The rate of stillbirth was calculated from the number of stillbirths divided by all births multiplied by 1000

${ }^{c}$ Early neonatal mortality rate is early neonatal mortality divided by total live births multiplied by 1000

'Late neonatal mortality rate is late neonatal mortality divided by total live births multiplied by 1000

${ }^{\mathrm{e}}$ Neonatal mortality rate is neonatal mortality divided by total live births multiplied by 1000

fPerinatal mortality rate is stillbirths plus mortality within the first week of life per 1000 births

${ }^{9}$ Extended perinatal mortality rate is stillbirths plus mortality within the first 28 days of life per 1000 births
"We double checked our findings by re-normalising the sampling weights for each year of survey to add up to 1 . This process involved computing the total sum of weights for each survey round and divide each year of survey sampling weights with the total sum of weights. The results obtained from using each year of survey sampling weights presented in the manuscript and those obtained from re-normalized sampling weights were similar (see Additional files 1 and 2).

\section{Results}

Over the study period (2001-2016), PMR was 42 (95\% CI: 39, 44) per 1000 births; whereas EPMR was 49 (95\% CI: 46, 51) per 1000 births (Table 1). PMR and EPMR decreased significantly in 2011 and 2016 compared to 2001 (Fig. 2a, b). Similarly, PMR and EPMR decreased significantly in 2016 compared to 2006. However, there was no significant decrease in PMR and EPMR in 2016 compared to 2011.

Mothers residing in the mountains reported significantly higher PMR and EPMR than those who resided in the Terai or the hills (Table 2). Lower rates of perinatal and extended perinatal mortality were observed among women with aged between 25 to 49 years. Households with improved sanitation facilities, as well as those who used natural gas for cooking at home reported lower PMRs and EPMRs. Women who currently used contraceptives also reported lower PMR and EPMR.

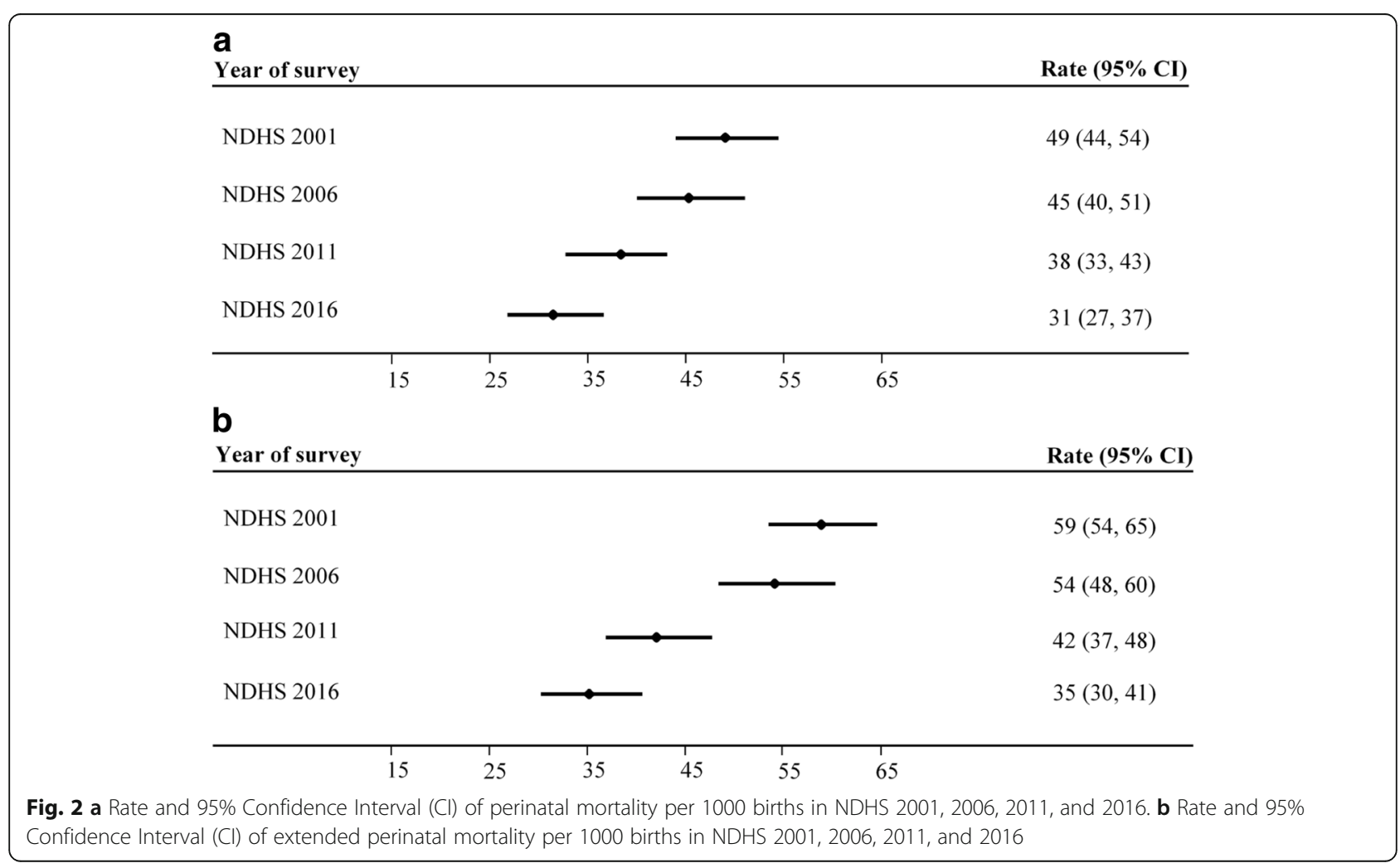


Table 2 Characteristics of study population as weighted counts, and Perinatal Mortality (PM) and Extended Perinatal Mortality (EPM) rates with 95\% Confidence Interval (Cl) in Nepal (2001-2016), ( $N=23,335)$

\begin{tabular}{|c|c|c|c|}
\hline Explanatory Variables & $\mathrm{N}^{\mathrm{a}}$ & PM Rate $(95 \% \mathrm{Cl})$ & EPM Rate $(95 \% \mathrm{Cl})$ \\
\hline \multicolumn{4}{|l|}{ Community level factor } \\
\hline \multicolumn{4}{|l|}{ Types of residence } \\
\hline Urban & 4395 & $31(28,33)$ & $34(32,37)$ \\
\hline Rural & 18,940 & $44(42,47)$ & $52(49,55)$ \\
\hline \multicolumn{4}{|l|}{ Ecological zone } \\
\hline Terai & 12,169 & $42(40,45)$ & $49(46,52)$ \\
\hline Hill & 9319 & $38(35,40)$ & $45(42,47)$ \\
\hline Mountain & 1847 & $56(53,59)$ & $67(63,70)$ \\
\hline \multicolumn{4}{|l|}{ Socio-economic factor } \\
\hline \multicolumn{4}{|l|}{ Wealth index } \\
\hline Rich & 4946 & $26(24,28)$ & $29(27,31)$ \\
\hline Middle & 9644 & $44(41,47)$ & $51(48,54)$ \\
\hline Poor & 8745 & $48(45,51)$ & $57(54,60)$ \\
\hline \multicolumn{4}{|l|}{ Religion } \\
\hline Buddhist & 1601 & $31(28,33)$ & $41(39,44)$ \\
\hline Hindu & 19,639 & $42(40,45)$ & $49(46,52)$ \\
\hline Others $^{b}$ & 2096 & $45(42,48)$ & $48(45,51)$ \\
\hline \multicolumn{4}{|l|}{ Ethnicity } \\
\hline Brahmin/chettry & 6323 & $37(34,39)$ & $43(40,46)$ \\
\hline Dalit & 3716 & $51(48,54)$ & $61(58,64)$ \\
\hline Janajati & 7647 & $37(35,40)$ & $43(40,46)$ \\
\hline Madhesi & 5649 & $47(44,50)$ & $55(52,58)$ \\
\hline \multicolumn{4}{|l|}{ Mother education } \\
\hline Secondary or higher & 6151 & $29(27,32)$ & $33(31,36)$ \\
\hline Primary & 4148 & $42(39,45)$ & $48(45,51)$ \\
\hline No education & 13,036 & $47(45,50)$ & $56(53,59)$ \\
\hline \multicolumn{4}{|l|}{ Mother's literacy level $(N=23,333)$} \\
\hline Can read part or whole of the sentence & 11,391 & $32(30,35)$ & $37(34,39)$ \\
\hline Cannot read & 11,942 & $51(48,54)$ & $60(57,63)$ \\
\hline \multicolumn{4}{|l|}{ Father education $(N=23,299)$} \\
\hline Secondary or higher & 11,382 & $36(33,38)$ & $41(38,44)$ \\
\hline Primary & 5923 & $43(40,46)$ & $51(48,54)$ \\
\hline No education & 5994 & $52(49,55)$ & $61(58,64)$ \\
\hline \multicolumn{4}{|l|}{ Mother occupation $(N=23,333)$} \\
\hline Not working & 5906 & $34(32,36)$ & $39(36,41)$ \\
\hline Agriculture & 15,157 & $45(43,48)$ & $53(50,56)$ \\
\hline Non- Agriculture ${ }^{c}$ & 2270 & $36(33,38)$ & $41(38,43)$ \\
\hline \multicolumn{4}{|l|}{ Maternal factor } \\
\hline \multicolumn{4}{|l|}{ Mother's current age (years) } \\
\hline $25-49$ & 14,131 & $39(37,42)$ & $45(42,47)$ \\
\hline $15-18$ & 821 & $67(64,70)$ & $77(73,80)$ \\
\hline $19-24$ & 8383 & $44(41,46)$ & $53(50,56)$ \\
\hline
\end{tabular}

Maternal marital status 
Table 2 Characteristics of study population as weighted counts, and Perinatal Mortality (PM) and Extended Perinatal Mortality (EPM) rates with 95\% Confidence Interval (Cl) in Nepal (2001-2016), ( $N=23,335)$ (Continued)

\begin{tabular}{|c|c|c|c|}
\hline Explanatory Variables & $N^{a}$ & PM Rate (95\% Cl) & EPM Rate $(95 \% \mathrm{Cl})$ \\
\hline Not currently married & 219 & $32(30,34)$ & $32(30,34)$ \\
\hline Currently married & 23,116 & $42(39,45)$ & $49(46,52)$ \\
\hline \multicolumn{4}{|l|}{ Birth order and birth interval } \\
\hline 2nd/3rd birth order, interval $>2$ years & 7065 & $19(18,21)$ & $24(22,26)$ \\
\hline 1st birth order & 7074 & $36(33,38)$ & $44(41,46)$ \\
\hline $2 n d / 3 r d$ birth order, interval $\leq 2$ years & 2613 & $42(39,45)$ & $52(49,55)$ \\
\hline 4th or higher birth order, interval $>2$ years & 1727 & $82(78,85)$ & $86(83,90)$ \\
\hline 4 th or higher birth order, interval $\leq 2$ years & 4856 & $45(42,47)$ & $59(56,62)$ \\
\hline \multicolumn{4}{|l|}{ Environmental factor } \\
\hline \multicolumn{4}{|l|}{ Types of drinking water source $(N=21,779)$} \\
\hline Piped water on premises & 2990 & $31(29,33)$ & $36(34,39)$ \\
\hline Other improved drinking water sources & 15,231 & $40(38,43)$ & $47(45,50)$ \\
\hline Unimproved drinking water sources & 1434 & $45(42,47)$ & $50(47,52)$ \\
\hline Surface drinking water sources & 2124 & $52(49,55)$ & $59(56,62)$ \\
\hline \multicolumn{4}{|l|}{ Types of sanitation facility $(N=21,775)$} \\
\hline Improved sanitation facilities & 7931 & $30(27,32)$ & $34(31,36)$ \\
\hline Unimproved sanitation facilities & 1924 & $42(39,45)$ & $50(47,53)$ \\
\hline Open defecation & 11,920 & $47(45,50)$ & $56(53,59)$ \\
\hline \multicolumn{4}{|l|}{ Types of cooking fuel $(N=21,782)$} \\
\hline Natural gas & 3035 & $22(20,24)$ & $25(23,27)$ \\
\hline Biomass energy & 18,747 & $44(41,46)$ & $51(48,54)$ \\
\hline \multicolumn{4}{|l|}{ Health service factor } \\
\hline \multicolumn{4}{|l|}{ Number of antenatal care (ANC) visits $(N=23,164)$} \\
\hline $4+$ & 8442 & $29(27,32)$ & $34(32,37)$ \\
\hline$(1-3)$ & 8330 & $37(34,39)$ & $44(41,46)$ \\
\hline No ANC & 6392 & $40(37,42)$ & $49(47,52)$ \\
\hline \multicolumn{4}{|l|}{ Number of $T$ during pregnancy $(N=23,164)$} \\
\hline $2+\pi$ & 13,461 & $33(31,36)$ & $39(37,42)$ \\
\hline $1 \pi$ & 3551 & $34(32,36)$ & $40(38,43)$ \\
\hline Never & 6152 & $39(36,41)$ & $48(46,51)$ \\
\hline \multicolumn{4}{|l|}{ IFA supplementation during pregnancy $(N=23,168)$} \\
\hline Yes & 13,460 & $33(30,35)$ & $38(35,40)$ \\
\hline No & 9708 & $38(36,41)$ & $47(44,50)$ \\
\hline \multicolumn{4}{|l|}{ Place and assistance during delivery $(N=23,154)$} \\
\hline Health facility & 6816 & $31(29,34)$ & $35(33,37)$ \\
\hline Home delivery with skilled attendants ${ }^{d}$ & 167 & $48(45,51)$ & $54(51,57)$ \\
\hline Home delivery without skilled attendants & 16,171 & $36(34,39)$ & $44(42,47)$ \\
\hline \multicolumn{4}{|l|}{ Use of contraceptives } \\
\hline Yes & 8483 & $24(22,26)$ & $29(27,32)$ \\
\hline No & 14,852 & $52(49,55)$ & $60(57,63)$ \\
\hline
\end{tabular}

${ }^{a}$ Weighted study population. $\mathrm{N}$ varies between categories because of missing values

bother religion includes mainly Christians, Muslims, and Kirats

${ }^{c}$ Non-agriculture occupation includes skilled or professional jobs; ${ }^{\mathrm{d}}$ Skilled attendants: doctors/nurses/midwives 
Table 3 Unadjusted and adjusted Odd Ratios (OR) for factors associated with perinatal mortality in Nepal, 2001-2016 ( $N=23,335)$

\begin{tabular}{llll}
\hline Explanatory Variables & Unadjusted & & Adjusted \\
$\begin{array}{llll}\text { Year of survey } \\
\text { OR }(95 \% \mathrm{Cl})\end{array}$ & & OR $(95 \% \mathrm{Cl})$ \\
2001 & 1.00 (Reference) & & 1.00 (Reference) \\
2006 & $0.92(0.78,1.10)$ & & $0.95(0.78,1.16)$ \\
2011 & $0.77(0.64,0.93)$ & & $0.98(0.80,1.21)$ \\
2016 & $0.62(0.51,0.77)$ & & $0.72(0.56,0.92)$
\end{tabular}

Community level factor

Types of residence

$\begin{array}{ll}\text { Urban } & 1.00 \text { (Reference) } \\ \text { Rural } & 1.46(1.20,1.79)\end{array}$

Ecological zone

Terai

Hill

Mountain

Socio-economic factor

Wealth index

$\begin{array}{ll}\text { Rich } & 1.00 \text { (Reference) } \\ \text { Middle } & 1.73(1.41,2.13) \\ \text { Poor } & 1.93(1.57,2.39) \\ \text { Religion } & \\ \text { Buddhist } & 1.00 \text { (Reference) } \\ \text { Hindu } & 1.37(0.99,1.91) \\ \text { Others including } & 1.47(0.97,2.21) \\ \text { Muslim and Christian } & \end{array}$

Ethnicity

Brahmin/chettri

Dalit

Janajati

Madhesi

Mother education

Secondary or higher

Primary

$1.30(1.02,1.65)$

Mother's literacy level

Can read part or whole of the sentence

Cannot read

Father education

Secondary or higher

Primary

No education

Mother occupation

Not working

Agriculture

Non-agriculture
1.00 (Reference)

$1.44(1.13,1.82)$

$1.02(0.83,1.26)$

$1.31(1.07,1.62)$

1.00 (Reference)

$1.05(0.84,1.31)$

$1.28(0.99,1.65)$

1.00 (Reference)

$1.44(1.11,1.85)$

$1.64(1.33,2.03)$

1.00 (Reference)

$1.42(1.24,1.63)$

1.00 (Reference)

1.00 (Reference)

$1.02(0.83,1.26)$

$1.44(1.07,1.95)$

1.00 (Reference)

$1.21(1.00,1.46)$

$1.47(1.23,1.77)$

$1.28(1.05,1.56)$

$0.95(0.66,1.36)$
Table 3 Unadjusted and adjusted Odd Ratios (OR) for factors associated with perinatal mortality in Nepal, 2001-2016 ( $N=23,335)$ (Continued)

\begin{tabular}{llll}
\hline Explanatory Variables & \multicolumn{1}{l}{ Unadjusted } & & Adjusted \\
\cline { 1 - 1 } Maternal factor & OR $(95 \% \mathrm{Cl})$ & & OR $(95 \% \mathrm{Cl})$ \\
$\begin{array}{l}\text { Mother's current age (years) } \\
25-49\end{array}$ & 1.00 (Reference) & & 1.00 (Reference) \\
$15-18$ & $1.76(1.27,2.45)$ & & $1.99(1.30,3.09)$ \\
$19-24$ & $1.12(0.95,1.33)$ & & $1.71(1.39,2.11)$ \\
Maternal marital status & & \\
$\quad$ Not currently married & 1.00 (Reference) & \\
Currently married & $1.43(0.63,3.26)$ &
\end{tabular}

Birth order and birth interval

$\begin{array}{lcc}\begin{array}{l}\text { 2nd/3rd birth order, } \\ \text { interval > 2 years }\end{array} & 1.00 \text { (Reference) } & 1.00 \text { (Reference) } \\ \begin{array}{l}\text { 1st birth order } \\ \begin{array}{l}\text { 2nd/3rd birth order, } \\ \text { interval } \leq 2 \text { years }\end{array}\end{array} & 1.90(1.54,2.35) & 1.32(1.03,1.69) \\ \begin{array}{l}\text { 4th or higher birth order, } \\ \text { interval > 2 years }\end{array} & 4.48(3.67,5.47) & 3.27(2.58,4.15) \\ \begin{array}{l}\text { 4th or higher birth order, } \\ \text { interval } \leq 2 \text { years }\end{array} & 2.35(1.76,3.12) & 2.41(1.76,3.29) \\ & & \end{array}$

Environmental factor

Types of drinking water source

Piped water on premises

1.00 (Reference)

Other improved drinking

water sources

$1.30(1.00,1.68)$

Unimproved drinking

$1.45(1.00,2.12)$

water sources

$1.70(1.24,2.35)$

Surface drinking water sources

Types of sanitation facility

Improved sanitation facilities 1.00 (Reference)

Unimproved sanitation facilities $1.44(1.06,1.95)$

Open defecation

$1.63(1.37,1.94)$

Types of cooking fuel

$\begin{array}{lll}\text { Natural gas } & 1.00 \text { (Reference) } & 1.00 \text { (Reference) } \\ \text { Biomass energy } & 2.05(1.54,2.73) & 1.46(1.08,1.97)\end{array}$

Health service factor

Number of antenatal care (ANC) visits

$$
\begin{array}{ll}
4+ & 1.00 \text { (Reference) } \\
(1-3) & 1.25(1.04,1.51) \\
\text { No ANC } & 1.37(1.10,1.70)
\end{array}
$$

Number of $\Pi$ during pregnancy

$\begin{array}{ll}2+\pi & 1.00 \text { (Reference) } \\ 1 \pi & 1.02(0.80,1.30) \\ \text { Never } & 1.18(0.97,1.43)\end{array}$

IFA supplementation during pregnancy

Yes 1.00 (Reference)

No $\quad 1.18(0.99,1.41)$ 
Table 3 Unadjusted and adjusted Odd Ratios (OR) for factors associated with perinatal mortality in Nepal, 2001-2016 ( $N=23,335)$ (Continued)

\begin{tabular}{llll}
\hline Explanatory Variables & Unadjusted & & Adjusted \\
Place and assistance during delivery $(95 \% \mathrm{Cl})$ & & OR $(95 \% \mathrm{Cl})$ \\
Health facility & 1.00 (Reference) & \\
$\begin{array}{l}\text { Home delivery with skilled } \\
\text { attendants }\end{array}$ & $1.59(0.76,3.32)$ & \\
$\begin{array}{l}\text { Home delivery without skilled } \\
\text { attendants }\end{array}$ & $1.12(0.94,1.32)$ & \\
$\begin{array}{l}\text { Use of contraceptives } \\
\text { Yes }\end{array}$ & 1.00 (Reference) & 1.00 (Reference) \\
No & $2.25(1.87,2.70)$ & & 1.93 (1.61, 2.31) \\
\hline
\end{tabular}

\section{Multivariate analysis}

Table 3 shows unadjusted and adjusted Odd Ratios (OR) for the association between perinatal mortality and exploratory variables, while Table 4 summarizes the corresponding ORs for extended perinatal mortality.

\section{Factors associated with perinatal mortality (PM)}

After adjusting for potential explanatory variables, perinatal mortality has decreased significantly by $28 \%$ (aOR: 0.72; 95\% CI: 0.56, 0.92) between 2001 and 2016. Women residing in the mountain ecological zone and women of the dalit ethnic group had increased risk of perinatal mortality compared to those who reside in the terai ecological zone and belong to Brahmin/Chettri ethnic group. A significant increment of perinatal mortality was observed among women having 4th or higher birth order with any years of interval compared to women having 2nd or 3rd birth order with $>2$ years of interval. Women aged 15 to 18 years or 19 to 24 years, and those not using contraception reported higher risk of perinatal mortality compared to those with aged 25 to 49 years, and who were using contraception. Women who used biomass energy for cooking at home had significantly higher odds of having perinatal mortality compared to those who used natural gas for cooking.

In the final model of PM, when types of cooking fuel were removed and replaced by household wealth index, we found that women from the middle households were more likely to report PM (aOR: 1.44; 95\% CI: 1.13, 1.83) compared to their richer counterparts.

Factors associated with extended perinatal mortality (EPM) Our results showed similar factors to be associated with EPM as those mentioned for PM. We replaced household wealth index with types of cooking fuel in the final model; and our results indicated that women from middle households were more likely to report EPM (aOR: 1.42; 95\% CI: $1.13,1.78)$ compared to their richer counterparts.

\section{Discussion}

This study identified more distant factors associated with PM and EPM in Nepal. Over the study period (2001-2016), there has been a significant decline in PM and EPM. However, the pace of progress is not sufficient enough to achieve SDG target of 12 or fewer perinatal deaths per 1000 births by the year 2030. We found that the factors that were consistent across PM and EPM were ecological zone, household wealth index, birth order and birth interval; maternal age, use of contraceptives, and type of cooking fuel. Similarly, the study also found that maternal ethnic background was associated with PM; whereas maternal literacy level was found to be associated with EPM.

In this study, the odds of PM and EPM were significantly higher among women residing in the mountain ecological zone compared to those who lived in the terai ecological zone. This finding is consistent with a past study conducted in a landlocked country of Peru which has shown that high altitude $(\geq 3000 \mathrm{~m}$ above the sea level) was associated with perinatal mortality [26]. Similarly, a study conducted in Nepal revealed that mothers who lived in mountainous region, with altitude ranges from $4877 \mathrm{~m}$ to $8848 \mathrm{~m}$ above the sea level were significantly more likely to report an increased risk of perinatal mortality [27]. Aadditionally, higher perinatal mortality in the mountains could be connected to access to services. Absence of adequate medical facilities would be an important contributor to the increased risk of perinatal mortality due to difficulties in timely accessing maternal and newborn health care services including emergency obstetric care during labour.

Women who were illiterate had a higher risk of EPM. This finding was consistent with a prospective longitudinal study conducted in Northwest Ethiopia [19]. Similarly, a case-control study conducted in Mashonaland East Province of Zimbabwe revealed that mothers who completed Primary education or no schooling were 5.4 times more likely to report PM compared with educated mothers [28]. These findings contradict a study carried out in Bangladesh that used prospective data on maternal morbidity which indicated that women who completed secondary or more level of education reported higher risks of perinatal mortality compared with women with no schooling [29].

Higher PM and EPM among younger age women reported in this study were similar to those reported in a population-based nested case-control conducted in Ethiopia [30]. Younger women are more likely to receive inadequate health care including family planning than older women due to the low level of women's autonomy regarding health care decisions in the households [31], psychological problems and less social support from family members [32]. Higher odds of perinatal mortality among younger women may be due to inadequate weight gain during pregnancy, 
Table 4 Unadjusted and adjusted Odd Ratios (OR) for factors associated with extended perinatal mortality in Nepal, 2001-2016 $(N=23,335)$

\begin{tabular}{|c|c|c|}
\hline \multirow[t]{2}{*}{ Explanatory Variables } & \multirow{2}{*}{$\begin{array}{l}\text { Unadjusted } \\
\mathrm{OR}(95 \% \mathrm{Cl})\end{array}$} & \multirow{2}{*}{$\frac{\text { Adjusted }}{\text { OR }(95 \% \mathrm{Cl})}$} \\
\hline & & \\
\hline \multicolumn{3}{|l|}{ Year of survey } \\
\hline 2001 & 1.00 (Reference) & 1.00 (Reference) \\
\hline 2006 & $0.92(0.79,1.08)$ & $0.98(0.82,1.18)$ \\
\hline 2011 & $0.70(0.58,0.83)$ & $0.88(0.73,1.08)$ \\
\hline 2016 & $0.58(0.48,0.70)$ & $0.69(0.54,0.86)$ \\
\hline \multicolumn{3}{|l|}{ Types of residence } \\
\hline Urban & 1.00 (Reference) & \\
\hline Rural & $1.54(1.27,1.86)$ & \\
\hline \multicolumn{3}{|l|}{ Ecological zone } \\
\hline Terai & 1.00 (Reference) & 1.00 (Reference) \\
\hline Hill & $0.91(0.78,1.06)$ & $0.99(0.84,1.18)$ \\
\hline Mountain & $1.39(1.15,1.68)$ & $1.37(1.06,1.76)$ \\
\hline \multicolumn{3}{|l|}{ Socio-economic factor } \\
\hline \multicolumn{3}{|l|}{ Wealth index } \\
\hline Rich & 1.00 (Reference) & \\
\hline Middle & $1.66(1.33,2.08)$ & \\
\hline Poor & $1.53(1.13,1.81)$ & \\
\hline \multicolumn{3}{|l|}{ Religion } \\
\hline Buddhist & 1.00 (Reference) & \\
\hline Hindu & $1.21(0.89,1.63)$ & \\
\hline $\begin{array}{l}\text { Others including Muslim } \\
\text { and Christian }\end{array}$ & $1.18(0.80,1.74)$ & \\
\hline \multicolumn{3}{|l|}{ Ethnicity } \\
\hline Brahmin/chettri & 1.00 (Reference) & \\
\hline Dalit & $1.45(1.16,1.80)$ & \\
\hline Janajati & $1.00(0.83,1.22)$ & \\
\hline Madhesi & $1.28(1.05,1.57)$ & \\
\hline \multicolumn{3}{|l|}{ Mother education } \\
\hline Secondary or higher & 1.00 (Reference) & \\
\hline Primary & $1.46(1.14,1.86)$ & \\
\hline No education & $1.73(1.42,2.11)$ & \\
\hline \multicolumn{3}{|l|}{ Mother's literacy level } \\
\hline $\begin{array}{l}\text { Can read part or whole } \\
\text { of the sentence }\end{array}$ & 1.00 (Reference) & 1.00 (Reference) \\
\hline Cannot read & $1.51(1.33,1.72)$ & $1.23(1.05,1.45)$ \\
\hline \multicolumn{3}{|l|}{ Father education } \\
\hline Secondary or higher & 1.00 (Reference) & \\
\hline Primary & $1.27(1.08,1.50)$ & \\
\hline No education & $1.52(1.28,1.81)$ & \\
\hline \multicolumn{3}{|l|}{ Mother occupation } \\
\hline Not working & 1.00 (Reference) & \\
\hline Agriculture & $1.32(1.09,1.59)$ & \\
\hline Non-agriculture & $0.94(0.68,1.32)$ & \\
\hline
\end{tabular}

Table 4 Unadjusted and adjusted Odd Ratios (OR) for factors associated with extended perinatal mortality in Nepal, 2001-2016 $(N=23,335)$ (Continued)

\begin{tabular}{|c|c|c|}
\hline \multirow[t]{2}{*}{ Explanatory Variables } & Unadjusted & Adjusted \\
\hline & OR $(95 \% \mathrm{Cl})$ & OR $(95 \% \mathrm{Cl})$ \\
\hline \multicolumn{3}{|l|}{ Maternal factor } \\
\hline \multicolumn{3}{|l|}{ Mother's current age (years) } \\
\hline $25-49$ & 1.00 (Reference) & 1.00 (Reference) \\
\hline $15-18$ & $1.79(1.32,2.42)$ & $2.15(1.45,3.18)$ \\
\hline $19-24$ & $1.19(1.03,1.39)$ & $1.78(1.47,2.15)$ \\
\hline \multicolumn{3}{|l|}{ Maternal marital status } \\
\hline Not currently married & 1.00 (Reference) & \\
\hline Currently married & $1.68(0.74,3.82)$ & \\
\hline \multicolumn{3}{|l|}{ Birth order and birth interval } \\
\hline $\begin{array}{l}\text { 2nd/3rd birth order, } \\
\text { interval }>2 \text { years }\end{array}$ & 1.00 (Reference) & 1.00 (Reference) \\
\hline 1st birth order & $1.86(1.54,2.25)$ & $1.30(1.04,1.63)$ \\
\hline $\begin{array}{l}\text { 2nd/3rd birth order, } \\
\text { interval } \leq 2 \text { years }\end{array}$ & $2.17(1.72,2.74)$ & $1.80(1.41,2.31)$ \\
\hline $\begin{array}{l}\text { 4th or higher birth order, } \\
\text { interval > } 2 \text { years }\end{array}$ & $3.79(3.15,4.55)$ & $2.75(2.20,3.43)$ \\
\hline $\begin{array}{l}\text { 4th or higher birth order, } \\
\text { interval } \leq 2 \text { years }\end{array}$ & $2.52(1.96,3.25)$ & $2.56(1.94,3.38)$ \\
\hline
\end{tabular}

Environmental factor

Types of drinking water source

Piped water on premises

1.00 (Reference)

Other improved drinking

$1.33(1.05,1.69)$

water sources

Unimproved drinking

$1.40(0.97,2.00)$

water sources

Surface drinking water sources $\quad 1.68(1.25,2.26)$

Types of sanitation facility

Improved sanitation facilities

1.00 (Reference)

Unimproved sanitation facilities

$1.51(1.10,2.07)$

Open defecation

$1.70(1.44,2.01)$

Types of cooking fuel

Natural gas

1.00 (Reference)

1.00 (Reference)

Biomass energy

$2.11(1.60,2.79)$

$1.44(1.09,1.91)$
Number of antenatal care (ANC) visits

$4+$

1.00 (Reference)

$(1-3)$

$1.29(1.07,1.54)$

No ANC

$1.47(1.21,1.80)$

Number of $\Pi$ during pregnancy

$\begin{array}{ll}2+\pi & 1.00 \text { (Reference) } \\ 1 \Pi & 1.03(0.83,1.29) \\ \text { Never } & 1.25(1.04,1.50)\end{array}$

IFA supplementation during pregnancy

Yes

1.00 (Reference)

No

$1.25(1.07,1.47)$ 
Table 4 Unadjusted and adjusted Odd Ratios (OR) for factors associated with extended perinatal mortality in Nepal, 2001-2016 $(N=23,335)$ (Continued)

\begin{tabular}{|c|c|c|}
\hline \multirow[t]{2}{*}{ Explanatory Variables } & Unadjusted & Adjusted \\
\hline & $\mathrm{OR}(95 \% \mathrm{Cl})$ & $\mathrm{OR}(95 \% \mathrm{Cl})$ \\
\hline \multicolumn{3}{|l|}{ Place and assistance during delivery } \\
\hline Health facility & 1.00 (Reference) & \\
\hline $\begin{array}{l}\text { Home delivery with skilled } \\
\text { attendants }\end{array}$ & $1.69(0.87,3.31)$ & \\
\hline $\begin{array}{l}\text { Home delivery without skilled } \\
\text { attendants }\end{array}$ & $1.23(1.05,1.43)$ & \\
\hline \multicolumn{3}{|l|}{ Use of contraceptives } \\
\hline Yes & 1.00 (Reference) & 1.00 (Reference) \\
\hline No & $2.10(1.77,2.51)$ & $1.79(1.52,2.11)$ \\
\hline
\end{tabular}

low socioeconomic status, and inadequate prenatal care [33]. In Nepal, early marriage and pregnancy is still a common practice with about $17 \%$ of girls married before the age of 19 years [15]. Early marriage is a deeply rooted and widely practised socio-cultural norm. For example, in the regional part of Nepal, bride family are required to pay extra money when young unmarried girls grow older [34].

In agreement with our findings a previous study in Nepal and India showed that mothers with 4th or higher birth order had higher probability of perinatal death $[9,35]$. Obstetric complications are important causes of perinatal mortality in South Asia [17]; and a previous study has suggested that women with 4th or higher birth order were at greater risk of having any obstetric complication compared to women with birth order $<3$ [36].

In Asia, while environmental factors (unimproved water, sanitation, and smoke from unimproved cooking fuel) are considered among the ten leading risks for disease [37], Nepal has made substantial improvements in the use of improved drinking water sources and sanitation facilities over the past 15 years [12-15]. Yet, the majority (over 65\%) of households in the same period have constantly been using biomass energy for cooking at home [12-15]. The finding of an increased risk of PM and EPM has also been reported in a hospital-based surveillance and case-control study, linked with a population survey in India [38]. Past studies suggested that chronic exposure to carbon monoxide from biomass energy will deteriorate newborn respiratory health that may lead to a lower chance of survival especially in the first month of infant life [39]. In Nepal, natural gas is expensive; and the use of natural gas is more prevalent among rich households [12-15]. Our study also revealed that women from a rich household wealth index were less likely to report PM and EMP compared to women from a lower household wealth index. Access to affordable renewal energy both at home and community could benefit health and thus help in reducing perinatal deaths.
A plausible reason for the finding of a higher PM among Dalit women may be because Dalits were ethnic minority women, less empowered, and socio-economically marginalised with limited ability to improve their health and the health of their newborn. It has been documented that $90 \%$ of total Dalit populations living below the poverty line in Nepal have limited access to health care [40].

The higher perinatal mortality rate in home births with skilled birth attendants compared to those without skilled birth attendants in this study may be the reflection of high-risk pregnancies which may be difficult to manage in home settings.

This study has many strengths, including the use of the pooled Nepal DHS (2001-2016) with large sample sizes, and higher response rates (almost 97\%). Second, the study investigated factors associated with PM and EPM using household national-wide representative surveys; and findings from a population-based study can be used by public health practitioners to formulate and inform national level policies to improve fetal and newborn survival. Third, the same questionnaires were used to collect information in all four surveys which increase accuracy and promote coherence of the data used for analysis. Despite these strengths, this study also has limitations. First, information about duration of pregnancy and birth intervals (which may be complex for illiterate women) may lead to reporting bias. Second, twin stillbirths are recorded as one stillbirth in the calendar that may undercount the number of total stillbirths, but they are very rare events. Third, this study is limited by the fact that data on important explanatory variables such as a history of previous stillbirth, prematurity, fetal growth, low birthweight, maternal anaemia, obstetric complications such as breech delivery, and birth asphyxia were not collected in the four NDHS. Fourthly, maternal body mass index, an important confounder, was not included in our multivariate analysis due to large numbers of missing data (23\%) which if included could have biased the results.

\section{Conclusions}

Our analyses examined more distant factors associated with PM and EPM in Nepal using pooled population-based surveys for the year 2001, 2006, 2011, and 2016. Women who lived in the mountains, women who did not use contraceptives at the time of the survey, younger women, and women having 4th or higher birth order had significantly higher risks of PM and EPM. At household level, educating illiterate women about the benefits of using contraceptives is required to further reduce perinatal mortality. At community level, modern energy technologies such as the use of liquefied petroleum gas or electricity to all households may help to reduce perinatal mortality; and these interventions should target rural women and women from low socioeconomic households. 


\section{Additional files}

Additional file 1: Adjusted Odd Ratios (aOR) for factors associated with perinatal mortality in Nepal, 2001-2016 ( $N=23,335)$. (DOCX $19 \mathrm{~kb})$

Additional file 2: Adjusted Odd Ratios (aOR) for factors associated with extended perinatal mortality in Nepal, 2001-2016 ( $N=23,335)$. (DOCX 19 kb)

\section{Abbreviations}

ANC: Antenatal Care; EPM: Extended Perinatal Mortality; EPMR: Extended Perinatal Mortality Rate; IFA: Iron and Folic Acid; NDHS: Nepal Demographic and Health Survey; OR: Odd Ratio; PM: Perinatal Mortality; PMR: Perinatal Mortality Rate; $\Pi$ : Tetanus Toxoid

\section{Acknowledgements}

The authors are grateful to Measure DHS, ICF International, Rockville, Marylands, USA for providing the data of NDHS (2001-2016) for this study.

\section{Funding}

This study did not receive any funding from any agency in the public, commercial, or not for-profit sectors.

\section{Availability of data and materials}

The first author lodged a request application via online DHS program (https://dhsprogram.com/data/available-datasets.cfm) to use NDHS data (2001-2016) for this study, and permission was granted. The authors were not able to share the data directly.

\section{Authors' contributions}

PRG and KEA conceptualized the study. PRG performed the data analysis and drafted the manuscript. PRG, KEA, AMNR, MKN, MD and CRG critically reviewed the manuscript and also involved in editing and writing of the manuscript. All authors read and approved the final manuscript.

\section{Ethics approval and consent to participate}

This study is a secondary analysis of the NDHS data. The NDHS obtained ethical clearance from the Ethical Review Board of Nepal Health Research Council, Kathmandu and ICF Institutional Review Board, Maryland, USA. Data for this study are free to download and use by completing a request application via online DHS program (https://dhsprogram.com). The first author got permission from online DHS program to use data for this study. All four NDHS received informed consent from all the study participants, and the process for obtaining informed consent is also available from https://www.dhsprogram.com/WhatWe-Do/Protecting-the-Privacy-of-DHS-Survey-Respondents.cfm.

\section{Consent for publication}

Not applicable.

\section{Competing interests}

The authors declare that they have no competing interests. KEA is a member of the editorial board (Associate Editor) of BMC Pregnancy and Childbirth, and does not have any role in the journal review and decision making process for this manuscript.

\section{Publisher's Note}

Springer Nature remains neutral with regard to jurisdictional claims in published maps and institutional affiliations.

\section{Author details}

${ }^{1}$ School of Science and Health, Western Sydney University, Locked Bag1797, Penrith, NSW 2571, Australia. ${ }^{2}$ School of Social Sciences and Psychology, Western Sydney University, Locked Bag1797, Penrith, NSW 2571, Australia. ${ }^{3}$ Sydney School of Public Health, University of Sydney, Edward Ford Building (A27), Sydney, NSW 2006, Australia.
Received: 5 April 2018 Accepted: 1 March 2019

Published online: 11 March 2019

\section{References}

1. World Health Organization. Neonatal and perinatal mortality: country, regional and global estimates. Geneva: WHO; 2006.

2. Wang $H$, Bhutta ZA, Coates MM, Coggeshall M, Dandona L, Diallo K, et al. Global, regional, national, and selected subnational levels of stillbirths, neonatal, infant, and under-5 mortality, 1980-2015: a systematic analysis for the Global Burden of Disease Study 2015. Lancet 2016;388:1725.

3. Mason E, McDougall L, Lawn JE, Gupta A, Claeson M, Pillay Y, et al. From evidence to action to deliver a healthy start for the next generation. Lancet. 2014;384:455-67.

4. Bhutta ZA, Das JK, Bahl R, Lawn JE, Salam RA, Paul VK, et al. Can available interventions end preventable deaths in mothers, newborn babies, and stillbirths, and at what cost? Lancet. 2014;384:347-70.

5. Fikree FF, Gray RH. Demographic survey of the level and determinants of perinatal mortality in Karachi, Pakistan. Paediatr Perinat Epidemiol. 1996;10:86-96.

6. Khan MN, Rahman MM, Shariff AA, Rahman MM, Rahman MS, Rahman MA Maternal undernutrition and excessive body weight and risk of birth and health outcomes. Arch Public Health. 2017;75:12

7. Manandhar DS, Osrin D, Shrestha BP, Mesko N, Morrison J, Tumbahangphe KM, et al. Effect of a participatory intervention with women's groups on birth outcomes in Nepal: cluster-randomised controlled trial. Lancet. 2004: 364:970-9.

8. Manandhar SR, Ojha A, Manandhar DS, Shrestha B, Shrestha D, Saville N, et al. Causes of stillbirths and neonatal deaths in Dhanusha district, Nepal: a verbal autopsy study. Kathmandu Univ Med J (KUMJ). 2010;8:62-72.

9. Geetha T, Chenoy R, Stevens D, Johanson R. A multicentre study of perinatal mortality in Nepal. Paediatr Perinat Epidemiol. 1995:9:74-89.

10. Suwal A. Obstetric and perinatal outcome of teenage pregnancy. JNHRC. 2012;10:52-6.

11. Shrestha M, Manandhar D, Dhakal S, Nepal N. Two year audit of perinatal mortality at Kathmandu medical college teaching hospital. Kathmandu Univ Med J. 2006:4:176-81.

12. Ministry of Health [Nepal], New ERA, and ORC Macro. 2002. Nepal Demographic and Health Survey 2001. Calverton, Maryland, USA: Family Health Division, Ministry of Health; New ERA; and ORC Macro.

13. Ministry of Health and Population (MOHP) [Nepal], New ERA, and Macro International Inc. 2007. Nepal Demographic and Health Survey 2006 Kathmandu, Nepal: Ministry of Health and Population, New ERA, and Macro International Inc

14. Ministry of Health and Population (MOHP) [Nepal], New ERA, and ICF International Inc. 2012. Nepal Demographic and Health Survey 2011. Kathmandu, Nepal: Ministry of Health and Population, New ERA, and ICF International, Calverton, Maryland.

15. Ministry of Health and Population (MOHP) [Nepal], New ERA, and ICF International Inc. 2017. Nepal Demographic and Health Survey 2016. Kathmandu, Nepal: Ministry of Health and Population, New ERA, and ICF International, Calverton, Maryland.

16. Neasham D, Dolk H, Vrijheid M, Jensen T, Best N. Stillbirth and neonatal mortality due to congenital anomalies: temporal trends and variation by small area deprivation scores in England and Wales, 1986-96. Paediatr Perinat Epidemiol. 2001:15:364-73.

17. Ghimire PR, Agho K, Akombi B, Wali N, Dibley M, Raynes-Greenow C, et al. Perinatal mortality in South Asia: systematic review of observational studies. Int J Environ Res. 2018;15:1428.

18. Nisha MK, Alam A, Raynes-Greenow C. Variations in perinatal mortality associated with different polluting fuel types and kitchen location in Bangladesh. Int J Occup Environ Health. 2018;24:47-54

19. Andargie G, Berhane $Y$, Worku A, Kebede $Y$. Predictors of perinatal mortality in rural population of Northwest Ethiopia: a prospective longitudinal study. BMC Public Health. 2013;13:168.

20. Mosley WH, Chen LC. An analytical framework for the study of child survival in developing countries. Popul Dev Rev. 1984:10:25-45.

21. Abir T, Agho KE, Ogbo FA, Stevens GJ, Page A, Hasant MA, et al. Predictors of stillbirths in Bangladesh: evidence from the 2004-2014 nation-wide household surveys. Glob Health Action. 2017;10:1410048. 
22. Filmer $D$, Pritchett LH. Estimating wealth effects without expenditure data-or tears: an application to educational enrollments in states of India. Demography. 2001;38:115-32.

23. UNICEF/WHO. Progress on Sanitation and Drinking-Water: 2015 Update and MDG assessment. Geneva: UNICEF/WHO; 2015.

24. Skrondal A, Rabe-Hesketh S. Generalized latent variable modeling: multilevel, longitudinal, and structural equation models. Chapman and Hall/ CRC; 2004.

25. Victora CG, Huttly SR, Fuchs SC, Olinto M. The role of conceptual frameworks in epidemiological analysis: a hierarchical approach. Int J Epidemiol. 1997;26:224-7.

26. Gonzales GF, Tapia V, Carrillo CE. Stillbirth rates in Peruvian populations at high altitude. Int J Gynaecol Obstet. 2008;100:221-7.

27. Ghimire PR, Agho KE, Renzaho A, Christou A, Nisha MK, Dibley M, et al. Socio-economic predictors of stillbirths in Nepal (2001-2011). PLoS One. 2017;12:e0181332.

28. Tachiweyika E, Gombe N, Shambira G, Chadambuka A, Mufuta T, Zizhou S. Determinants of perinatal mortality in Marondera district, Mashonaland East Province of Zimbabwe, 2009: a case control study. Pan Afr Med J. 2011;8:7.

29. Bari W, Chowdhury RI, Islam MA, Chakraborty N, Akhter HA. The differentials and determinants of perinatal mortality in rural Bangladesh. Eur J Contracept Reprod Health Care. 2002;7:216-22.

30. Yirgu R, Molla M, Sibley L, Gebremariam A. Perinatal mortality magnitude, determinants and causes in west Gojam: population-based nested casecontrol study. PLoS One. 2016;11:e0159390.

31. Sharma AK, Verma K, Khatri S, Kannan A. Determinants of pregnancy in adolescents in Nepal. Indian J Pediatr. 2002;69:19-22.

32. Choe MK, Thapa S, Mishra V. Early marriage and early motherhood in Nepal. J Biosoc Sci. 2005;37:143-62.

33. Weng Y-H, Yang C-Y, Chiu Y-W. Risk assessment of adverse birth outcomes in relation to maternal age. PLoS One. 2014;9:e114843.

34. Shrestha R. Maternal mortality in Nepal: addressing the issue. Inquiries J. 2012:4:1-4.

35. Viswanath K, Ps R, Chakraborty A, Prasad JH, Minz S, George K. A community based case control study on determinants of perinatal mortality in a tribal population of southern India. Rural Remote Health. 2015;15:3388.

36. Bai J, Wong FW, Bauman A, Mohsin M. Parity and pregnancy outcomes. Am J Obstet Gynecol. 2002;186:274-8.

37. Guilbert JJ. The world health report 2002 - reducing risks, promoting healthy life. Educ Health. 2003;16:230.

38. Mavalankar DV, Trivedi C, Gray RH. Levels and risk factors for perinatal mortality in Ahmedabad, India. Bull World Health Organ. 1991;69:435.

39. Kim K-H, Jahan SA, Kabir E. A review of diseases associated with household air pollution due to the use of biomass fuels. J Hazard Mater. 2011;192:425-31.

40. Bishwakarma P. The situation analysis for dalit women of Nepal. National Seminar on Raising Dalit Participation in governance Centre for Economic and Technical Studies; 2004.

Ready to submit your research? Choose BMC and benefit from:

- fast, convenient online submission

- thorough peer review by experienced researchers in your field

- rapid publication on acceptance

- support for research data, including large and complex data types

- gold Open Access which fosters wider collaboration and increased citations

- maximum visibility for your research: over $100 \mathrm{M}$ website views per year

At $\mathrm{BMC}$, research is always in progress.

Learn more biomedcentral.com/submissions 